\title{
Capacidade combinatória em cenoura para componentes de produção e tolerância à queima-das-folhas
}

Agnaldo DF Carvalho; Giovani O Silva; Ricardo B Pereira; Jadir B Pinheiro; Jairo V Vieira

Embrapa Hortaliças, C. Postal 218, 70359-970 Brasília-DF; agnaldo.carvalho@embrapa.br (autor para correspondência); giovani. olegario@embrapa.br; ricardo-borges.pereira@embrapa.br; jadir.pinheiro@embrapa.br; jairo.vieira@embrapa.br

\section{RESUMO}

A utilização de híbridos de cenoura é uma demanda crescente no mercado brasileiro de sementes por aliarem maior precocidade e uniformidade, além da produtividade. Objetivou-se avaliar os efeitos da capacidade combinatória entre linhagens de cenoura para componentes de produção e tolerância à queima-das-folhas. Os cruzamentos foram realizados em um dialelo parcial $5 \times 2$, sendo utilizadas cinco linhagens macho-estéreis de origem temperada e dois genitores macho-férteis de origem tropical do programa de melhoramento da Embrapa Hortaliças. O experimento foi conduzido no campo experimental da Embrapa Hortaliças na safra 2011/12. Foi utilizado o delineamento de blocos ao acaso com três repetições. A parcela experimental foi constituída de um canteiro com 1,0 m de largura por 3,0 m de comprimento. Os dez híbridos e seus genitores masculinos foram avaliados quanto à tolerância à queima-das-folhas aos 90 dias após a semeadura e às produtividades total e comercial de raízes, razão entre ambas, peso, comprimento e diâmetro médio de raízes comerciais, aos 100 dias da semeadura. Realizou-se a análise de variância e as estimativas dos efeitos da capacidade geral (CGC) e específica de combinação (CEC). Ocorreram diferenças significativas entre híbridos para a maioria dos caracteres avaliados. Foram detectados efeitos predominantes da CGC sobre CEC para maioria dos caracteres componentes de produção: peso de raízes comerciais $\left(\mathrm{PRC}, \mathrm{t} \mathrm{ha}^{-1}\right)$, peso de raízes totais (PRT, $\left.\mathrm{t} \mathrm{ha}^{-1}\right)$, relação entre PRC sobre PRT (PROP), peso médio das raízes comerciais (PMR), comprimento médio das raízes comerciais (CMR) e diâmetro médio das raízes comerciais (DMR). Os efeitos da CEC foram significativos para tolerância à queima-das-folhas. Pode-se considerar que as linhagens macho-estéreis CNPH-11 e CNPH-72 e a linhagem masculina CNPH36 são as mais promissoras para serem utilizadas em programas de melhoramento visando a obtenção de híbridos.

Palavras chave: Daucus carota, cruzamentos dialélicos, capacidade combinatória, híbridos.

\section{ABSTRACT \\ Combining ability of carrot lineages for production components and tolerance to leaf blight}

The use of hybrid carrots is a growing demand in the Brazilian market of seeds because they combine earliness and uniformity, as well as yield. We evaluated the effects of combining ability between carrot lineages for production components and tolerance to leaf blight. The crosses were carried out in a partial diallel $5 \times 2$, using five male-sterile lines of temperate and two male-fertile parents of tropical origin of the breeding program of Embrapa Hortaliças. The experiment was conducted at the experimental field of Embrapa Vegetables in the season 2011/12. The experimental designed was randomized blocks with three replications. The experimental plot consisted of a bed $1.0 \mathrm{~m}$ wide by $3.0 \mathrm{~m}$ in length. The ten hybrids and their male parents were evaluated for tolerance to leaf blight at 90 days after sowing. At 100 days plants were harvested and measured total and marketable roots yield, the ratio between them, weight, length and diameter of marketable roots. The analysis of variance was performed and the effects of general combining ability (GCA) and specific combining ability (SCA) were estimated. There were significant differences among hybrids for most traits. We detected predominant effects of GCA over SCA for most of yield components characters: weight of marketable roots (WMR, $\mathrm{tha}^{-1}$ ), total weight of roots (TWR, $\left.\mathrm{t} \mathrm{ha}^{-1}\right)$, the relationship between WMR and TWR (PROP), mean weight of marketable roots (MWM), mean marketable root length (MRL) and mean marketable root diameter (MRD). SCA effects were significant for the tolerance to leaf blight. From these results we concluded that the male sterile lineages CNPH-11 and CNPH-72 and the male lineage CNPH-36 are the most promising for use in breeding programs aiming to produce hybrids.

Keywords: Daucus carota, general combining ability, specific combining ability, hybrids.

(Recebido para publicação em 8 de fevereiro de 2013; aceito em 16 de abril de 2014) (Received on February 8, 2013; accepted on April 16, 2014)

\begin{abstract}
A cenoura está entre as cinco principais hortaliças, de importância econômica, cultivadas no Brasil. Segundo a Embrapa Hortaliças, em 2008, mais de 25 mil ha foram cultivados com essa cultura o que gerou uma produção superior a 750 mil t de raízes comerciais (Anuário..., 2012).

No Brasil o grande avanço na cultura da cenoura se deve ao desenvolvimento da cultivar Brasília lançada pela Embrapa Hortaliças e ESALQ/USP no início
\end{abstract}

dos anos 80 (Vieira et al., 1983), que chegou a ocupar mais de $80 \%$ da área cultivada com cenoura de verão (Vilela et al., 1997). Depois da cultivar Brasília, a Embrapa Hortaliças manteve o foco no desenvolvimento de cultivares de verão, aprimorou as qualidades desta cultivar e lançou as cultivares Alvorada em 2000 e BRS Planalto em 2009 (Vieira et al., 2012).

Apesar do potencial agronômico das cultivares de polinização livre como
Brasília, Alvorada e BRS Planalto, o mercado de sementes atualmente demanda por cultivares híbridas, pois aliam maior precocidade e uniformidade, o que resulta em maior produtividade de raízes comerciais se comparada às cultivares de polinização livre (Vieira et al., 2009).

Para a produção de híbridos, o melhorista necessita gerar e avaliar grande quantidade de linhagens (Paterniani et al., 2010). Na maioria das vezes, esse 
profissional não consegue avaliar todas as combinações híbridas possíveis e precisa utilizar métodos da genética quantitativa, como os estudos das capacidades geral (CGC) e específica de combinação (CEC) para selecionar os genitores mais promissores na geração de híbridos (Cardoso, 2006). Por esses métodos é possível avaliar as linhagens com melhor comportamento médio dentro do conjunto de genitores testados ou com base no desempenho específico em uma combinação híbrida (Cruz et al., 2012).

As metodologias desenvolvidas para obter as estimativas dos parâmetros CGC e CEC foram propostas por Griffing (1956), Gardner \& Eberhart (1966) e Hayman (1954). Contudo, esses algoritmos envolvem grande número de cruzamentos e nem sempre fornecem as informações necessárias. Assim, foram propostos os esquemas de dialelo parcial e circulante que reduzem a quantidade de cruzamentos a serem realizados e fornecem informações sobre um conjunto relativamente grande de genitores (Cruz et al., 2012). No caso do dialelo parcial os cruzamentos envolvem genitores alocados em dois grupos e as inferências são realizadas para cada grupo separadamente.

Estudos envolvendo a capacidade combinatória em cenoura são raros na literatura. Simon \& Strandberg (1998) avaliaram cinco linhagens divergentes e amplamente utilizadas nos programas de melhoramento de cenoura dos EUA para tolerância a Alternaria e verificaram predomínio dos efeitos aditivos no controle desse caráter, mas com algum efeito de dominância. Em relação à produção, Duan et al. (1996) e posteriormente Guan et al. (2001) constataram efeitos de heterose e predomínio dos efeitos da CGC em trabalhos realizados com híbridos de cenoura, embora os efeitos de dominância (CEC) também contribuam significativamente na produção da maioria das combinações híbridas.

Desse modo, esse trabalho teve como objetivos estimar as capacidades geral e especifica de combinação entre linhagens de cenoura para componentes de produção e tolerância à queima-das-folhas.

\section{MATERIAL E MÉTODOS}

O esquema adotado para obtenção dos híbridos experimentais foi o dialelo parcial $(2 \times 5)$ em que as duas linhagens de origem tropical foram utilizadas como genitores masculinos (CNPH-20 e CNPH-36) e cruzadas com cada uma das cinco linhagens macho-estéreis de origem temperada (CNPH-11, CNPH65, CNPH-34, CNPH-13 e CNPH-72).

$\mathrm{O}$ experimento foi instalado em campo da Embrapa Hortaliças, em novembro de 2011. Doze genótipos de cenoura foram avaliados na safra 2011/12, sendo dez híbridos experimentais e dois genitores masculinos. O delineamento experimental utilizado foi de blocos ao acaso com três repetições. As parcelas experimentais foram constituídas de um canteiro com $3 \mathrm{~m}$ de comprimento por 1 $\mathrm{m}$ de largura. $\mathrm{O}$ sulco de plantio foi feito no sentido transversal ao canteiro em espaçamento duplo, sendo o espaçamento entre linhas simples de $10 \mathrm{~cm}$ e entre fileiras duplas de $20 \mathrm{~cm}$. O desbaste foi realizado aos 30 dias após a semeadura deixando um espaço de $5 \mathrm{~cm}$ entre plantas, o que resultou numa população equivalente a 890 mil plantas ha ${ }^{-1}$.

A adubação de plantio foi realizada com a formulação comercial 4-14-8 (NPK) na dose de 1,2 t ha-1. A adubação de cobertura foi realizada 35 dias após a semeadura com sulfato de amônio na dose de $400 \mathrm{~kg} \mathrm{ha}^{-1}$. O controle de plantas espontâneas foi realizado três dias após a semeadura com a aplicação do herbicida linurom, na dose de $900 \mathrm{~mL}$ i.a. ha ${ }^{-1}$. Na fase de desenvolvimento da cenoura o controle das plantas espontâneas foi realizado manualmente. A irrigação, quando necessária, foi realizada por aspersão com lâmina suficiente para manter o solo na capacidade de campo. Nenhum produto foi aplicado para controle de doenças fúngicas ou bacterianas. Os demais tratos culturais seguiram os normalmente recomendados para a cultura da cenoura de verão nas condições de cerrado brasileiro.

Aos 90 dias após a semeadura foi avaliada a severidade da queima-das-folhas utilizando-se uma escala de notas de 1 a 5 , onde $1=$ mais de $90 \%$ de severidade, $2=50$ a $90 \%$ de severidade, $3=12,5$ a $50 \%$ de severidade, $4=3,8$ a
$12,55 \%$ de severidade e $5=$ menos de $3,8 \%$ de severidade.

Aos 100 dias após a semeadura foi realizada a colheita e os seguintes caracteres foram mensurados: peso de raízes comerciais ( $\left.\mathrm{PRC}, \mathrm{t} \mathrm{ha}^{-1}\right)$, peso de raízes totais (PRT, $\mathrm{t}$ ha-1), relação entre PRC sobre PRT (PROP), severidade da queima-das-folhas (QDF), peso médio das raízes comerciais (PMR), comprimento médio das raízes comerciais (CMR) e diâmetro médio das raízes comerciais (DMR).

Os dados foram submetidos às pressuposições da análise de variância. No caso das variáveis PROP e QDF, estes foram transformados para arco seno e $\sqrt{x+0,5}$, respectivamente. A análise de variância foi realizada utilizando o software estatístico-genético Genes ${ }^{\circledR}$ (Cruz, 2006). A análise para dialelos parciais foi realizada utilizando a metodologia de Kempthorne \& Cunow (1961).

\section{RESULTADOS E DISCUSSÃO}

Os efeitos correspondentes aos quadrados médios dos cruzamentos, capacidade geral de combinação do grupo 1 (CGC-I) e do grupo 2 (CGC-2) e da capacidade específica de combinação entre os grupos I e II (CEC I x II) para os caracteres peso de raízes comerciais (PRC, $\mathrm{t} \mathrm{ha}^{-1}$ ), peso de raízes totais (PRT, $\left.\mathrm{t} \mathrm{ha}^{-1}\right)$, relação entre PRC sobre PRT (PROP, \%), severidade da queima-das-folhas (QDF, \%), peso médio das raízes comerciais (PMR, g), comprimento médio das raízes comerciais $(\mathrm{CMR}, \mathrm{cm})$ e diâmetro médio das raízes comerciais (DMR, cm) estão presentes na Tabela 1. Pôde-se observar que apenas para PMR não ocorreram diferenças significativas pelo teste de $\mathrm{F}$ entre os híbridos avaliados. Esse resultado demonstra o comportamento não coincidente dos híbridos para a maioria dos caracteres componentes de produção em cenoura. Para a CGC-I apenas o caráter DMR não apresentou diferenças entre os efeitos dos cinco parentais femininos. Já para os parentais masculinos (CGC-II) não ocorreram diferenças entre os caracteres PRT, QDF e CMR, demonstrando que as duas linhagens avaliadas apresentam 
Tabela 1. Quadrados médios da análise de variância dialélica para as variáveis peso de raízes comerciais $\left(\mathrm{PRC}, \mathrm{t}\right.$ ha $\left.\mathrm{P}^{-1}\right)$, peso de raízes totais $\left(\mathrm{PRT}, \mathrm{t} \mathrm{ha}^{-1}\right)$, relação entre PRC sobre PRT (PROP, \%), severidade à queima-das-folhas (QDF, \%), peso médio das raízes comerciais (PMR, g), comprimento médio das raízes comerciais $(\mathrm{CMR}, \mathrm{cm})$ e diâmetro médio das raízes comerciais (DMR, $\mathrm{cm})$ [mean squares diallel analysis for weight of marketable roots (PRC, $\mathrm{t} \mathrm{ha} \mathrm{a}^{-1}$ ), total weight of roots (PRT, $\left.\mathrm{t} \mathrm{ha}^{-1}\right)$, the relationship between CRP and PRT (PROP, $\%$ ), the severity of leaf blight (QDF, \%), average weight of marketable roots (PMR, g), average length of marketable roots (CMR, cm) and diameter of marketable roots (DMR, cm)]. Brasília, Embrapa Hortaliças, 2012.

\begin{tabular}{lcccccccc}
\hline FV & GL & PRC (t/ha) & PRT (t/ha) & PROP (\%) & QDF (\%) & PMR (g) & CMR (cm) & DMR (cm) \\
\hline Cruzamentos & 9 & $264,79^{* *}$ & $155,39^{*}$ & $0,02^{\text {ns }}$ & $1138,45^{* *}$ & $499,28^{\text {ns }}$ & $3,66^{*}$ & $0,07^{*}$ \\
CGC-I & 4 & $335,19^{* *}$ & $262,38^{* *}$ & $0,02^{\text {ns }}$ & $2136,31^{* *}$ & $443,36^{\text {ns }}$ & $6,38^{*}$ & $0,06^{\text {ns }}$ \\
CGC-II & 1 & $495,73^{* *}$ & $72,63^{\text {ns }}$ & $0,07^{*}$ & $11,56^{\text {ns }}$ & $1547,00^{*}$ & $0,01^{\text {ns }}$ & $0,37^{* *}$ \\
CEC IxII & 4 & $136,65^{\text {ns }}$ & $69,08^{\text {ns }}$ & $0,01^{\text {ns }}$ & $422,31^{*}$ & $293,26^{\text {ns }}$ & $1,85^{\text {ns }}$ & $0,01^{\text {ns }}$ \\
Resíduo & 35 & 68,66 & 68,67 & 0,01 & 84,60 & 255,17 & 1,79 & 0,03 \\
\hline Média & & 40,58 & 55,63 & 0,77 & 28,32 & 103,33 & 16,56 & 2,91 \\
CV (\%) & & 20,42 & 14,90 & 14,31 & 19,31 & 15,46 & 8,09 & 5,84 \\
\hline
\end{tabular}

Diferença significativa pelo teste de $\mathrm{F}: * * *$ significativo a 5 e $1 \%$ de probabilidade, respectivamente; ${ }^{\text {ns }}$ não significativo (significant difference

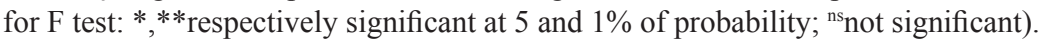

Tabela 2. Estimativas dos efeitos da capacidade geral de combinação (CGC) para sete linhagens de cenoura para as variáveis peso de raízes comerciais $\left(\mathrm{PRC}, \mathrm{t}_{\mathrm{a}}{ }^{-1}\right)$, peso de raízes totais $\left(\mathrm{PRT}, \mathrm{t} \mathrm{ha}^{-1}\right)$, relação entre PRC sobre PRT (PROP, \%), severidade à queima-das-folhas (QDF, \%), peso médio das raízes comerciais (PMR, g), comprimento médio das raízes comerciais (CMR, cm) e diâmetro médio das raízes comerciais (DMR, cm) [estimates of the effects of general combining ability (GCA) for seven lineages of carrot for weight of marketable roots $\left(\mathrm{PRC}, \mathrm{t} \mathrm{ha} \mathrm{a}^{-1}\right)$, total weight of roots (PRT, $\left.\mathrm{t} \mathrm{ha}^{-1}\right)$, the relationship between CRP and PRT (PROP, \%), severity of the leaf blight (QDF, $\%$ ), average weight of marketable roots (PMR, g), average length of marketable roots (CMR, $\mathrm{cm}$ ) and diameter of marketable roots (DMR, cm)]. Brasília, Embrapa Hortaliças, 2012.

\begin{tabular}{|c|c|c|c|c|c|c|c|c|}
\hline Grupo & Linhagem & PRC (t/ha) & PRT (t/ha) & PROP(\%) & QDF (\%) & PMR (g) & CMR (cm) & DMR $(\mathrm{cm})$ \\
\hline \multirow{5}{*}{1} & CNPH-11 & 6,88 & 6,87 & 0,02 & $-20,44$ & $-0,79$ & 0,32 & $-0,10$ \\
\hline & CNPH-65 & 1,57 & 1,07 & 0,02 & $-1,74$ & 9,18 & 1,08 & 0,02 \\
\hline & CNPH-34 & $-12,23$ & $-11,04$ & $-0,07$ & 30,47 & $-13,74$ & $-1,54$ & $-0,06$ \\
\hline & CNPH-13 & $-1,02$ & 1,52 & $-0,03$ & $-8,65$ & 4,64 & 0,61 & $-0,03$ \\
\hline & CNPH-72 & 4,80 & 1,58 & 0,07 & 0,36 & 0,71 & $-0,49$ & 0,16 \\
\hline \multirow{2}{*}{2} & CNPH-36 & 4,07 & 1,56 & 0,05 & $-0,62$ & 7,18 & 0,02 & 0,11 \\
\hline & CNPH-20 & $-4,07$ & $-1,56$ & $-0,05$ & 0,62 & $-7,18$ & $-0,02$ & $-0,11$ \\
\hline
\end{tabular}

potencial semelhante quanto à produtividade total, tolerância à queima-das-folhas e comprimento de raízes.

A significância dos efeitos da CGC-I demonstra a possibilidade de encontrar linhagens mais promissoras na combinação de híbridos de verão ou meia estação. Embora tenha origem de germoplasma temperado fica evidente a variabilidade desse conjunto de linhagens de produzir híbridos mais produtivos e/ ou mais tolerantes à queima-das-folhas. A variabilidade genética entre linhagens temperadas foi estudada por Simon \& Strandberg (1998). Esses autores encontraram diferenças altamente significativas entre estas e concluíram que as linhagens poderiam contribuir de forma distinta nos híbridos para a maior ou menor tolerância à queima-das-folhas.
Conforme os quadrados médios (Tabela 1) observaram-se predominância dos efeitos significativos para produtividade e resistência à queima-das-folhas principalmente para CGC. Esse fato já foi evidenciado por Guan et al. (2001), que observaram a produção, a coloração e o comprimento de raízes como caracteres que expressam maiores valores para a capacidade geral de combinação em comparação com a capacidade específica de combinação e contribuem significativamente para os programas de melhoramento.

Na Tabela 1, para PRC, PRT e QDF observaram-se efeitos aditivos predominantes (razão entre CGC/CEC) em relação aos efeitos de dominância, embora esse último também tenha efeito significativo. Resultados semelhantes foram relatados por Vieira et al. (1991) quando avaliaram famílias de meias-irmãs para tolerância à queima-das-folhas e destacaram os efeitos aditivos nos ganhos com seleção para esse caráter. Simon \& Strandberg (1998) encontraram valores duas vezes superior para os quadrados médios da CGC sobre CEC e salientaram que os efeitos aditivos dos genes são mais importantes que os efeitos de dominância, embora estes também afetem a expressão do caráter. Para produção, Duan et al. (1996) avaliaram um dialelo parcial 3x4 entre cruzamentos de linhagens macho-estéreis com linhagens macho-férteis de cenoura e encontraram efeitos significativos para heterose. Diante dos resultados os autores comentaram a predominância dos efeitos da CGC sobre CEC destacando 
o comportamento específico de alguns cruzamentos, o que evidencia a contribuição da CEC para a manifestação do caráter.

Para a capacidade geral de combinação (CGC) das linhagens dos grupos 1 e 2 (Tabela 2) em relação ao grupo de genitoras do grupo 1 chama atenção o comportamento das linhagens CNPH11 e CNPH-72. A linhagem CNPH-11 aumentou em quase 7,0 $\mathrm{t} \mathrm{ha}^{-1}$ as produtividades total e comercial de raízes, reduziu a severidade da queima-das-folhas e contribuiu para o aumento do comprimento das raízes. Já CNPH-72 contribuiu para aumentar a produtividade de raízes comerciais em 4,8 $\mathrm{t} \mathrm{ha}^{-1}$ e obteve considerável contribuição para aumentar a proporção de raízes comerciais (7,0\%). A linhagem CNPH-34 foi a que se mostrou menos promissora na utilização como genitora, pois, diminuiu a PRC (-12,23 t ha-1), a PRT $(-11,04 \mathrm{t}$ $\left.\mathrm{ha}^{-1}\right)$, a PROP $(-7 \%)$ e CMR $(-1,54 \mathrm{~cm})$ e aumentou a QDF $(30,47 \%)$. Entre as linhagens do grupo 2 para os caracteres em estudo ficou evidente a superioridade do genitor CNPH-36. Este foi superior ao genitor $\mathrm{CNPH}-20$ para todos os caracteres estudados.

Conforme a Tabela 1 apenas para QDF os quadrados médios de CEC foram significativos $(\mathrm{F} \leq 0,05)$. Desse modo nota-se o comportamento do híbrido CNPH-34xCNPH-20 que, embora seus genitores tenham apresentado desempenho inferior com base na CGC, na combinação conseguiu reduzir a severidade da QDF em 21,3\% em comparação com o híbrido CNPH-34xCNPH-36 (dados não apresentados). Outro híbrido que apresentou diferença marcante para esse caráter foi a combinação CNPH-13xCNPH-36 que foi $24,30 \%$ mais tolerante à queima-das-folhas do que o híbrido CNPH-13xCNPH-20.Os efeitos significativos para a CGC e CEC para QDF já foram relatados por Simon \& Strandberg (1998), ocasião em que os autores verificaram uma predominância dos efeitos da CGC sobre CEC e que os genitores mais tolerantes, embora tenham encontrados algumas exceções, conseguem transmitir esse fenótipo para as combinações híbridas. Em relação à seleção de genitores mais tolerantes à queima-das-folhas para produção de híbridos de verão, essa característica deve ser considerada, pois segundo Brito et al. (1997) e Pereira et al. (2012), a desfolha causada pela queima-das-folhas reflete em menor produtividade e qualidade de raízes.

\section{REFERÊNCIAS}

ANUÁRIO BRASILEIRO DE HORTALIÇAS. 2012. Brazilian Vegetable Yearbook. Santa Cruz do Sul: Gazeta. 88p.

BRITO CH; POZZA EA; JULIATTI FC; LUZ JMQ; PAES JMV. 1997. Resistência de cultivares de cenoura (Daucus carota) a queima-das-folhas durante o verão. Revista Ceres 44: 371-379.

CARDOSO AII. 2006. Dialelo entre linhagens de uma população de pepino do tipo 'Caipira'. Horticultura Brasileira 24: 259-263.

CRUZ CD. 2006. Programa Genes: Biometria. Viçosa: UFV. 382p.

CRUZ CD; REGAZZI AJ; CARNEIRO, PCS. 2012. Modelos biométricos aplicados ao melhoramento genético. 4.ed. Viçosa: UFV. $514 \mathrm{p}$.

DUAN Y; WANG Y; REN X; DU G. 1996. Analyze of heterosis and combining ability for main yield characteristics in carrot. China Vegetables 02: 1-7.

GARDNER CO; EBERHART SA. 1966. Analysis and interpretation of the variety cross diallel and related populations. Biometrics 22:439452.

GRIFFING B. 1956. Concept of general and specific combining ability in relation to diallel crossing systems. Australian Journal of Biological Science. 9: 463:493.

GUAN C; YIN L; GU Z; CHEN L. 2001. Study on heterosis of single root weight and combining ability of main economic characteristics in carrot. Tianjin Agricultural Sciences 4: 8-14.

HAYMAN, B I. 1954. The analysis of variances of diallel tables. Biometrics 10: 235-234.

KEMPTHORNE O; CUNOW RN. 1961. The partial diallel cross. Biometrics 17: 229-250.

PATERNIANI $M E A G Z$; FERREIRA E $A$; DUARTE AP; GALLO PB. 2010. Potencial de híbridos top cross de milho no estado de São Paulo. Revista Brasileira de Milho e Sorgo 9: 163-176.

PEREIRA RB; CARVALHO ADF; PINHEIRO JB; SILVA GO; VIEIRA JV. 2012. Resistência de populações de cenoura à queima-das-folhas com diferentes níveis de germoplasma tropical. Horticultura Brasileira 30: 489-493.

SIMON PW; STRANDBERG JO. 1998. Diallel analysis of resistance in carrot to Alternaria leaf blight. Journal of the American Society for Horticultural Science 123: 412-415.

VIEIRA JV; CASALI VWD; MILAGRES JC; CARDOSO AA; REGAZZI AJ. 1991. Heritability and genetic gain for resistance to leaf blight in carrot (Daucus carota) populations evaluated at different times after sowing. Revista Brasileira de Genética 14: 501-508.

VIEIRA JV; DELLA VECCHIA PT; IKUTA H. 1983. Cenoura Brasília. Horticultura Brasileira 1: 42.

VIEIRA JV; SILVA GO; BOITEUX LS; SIMON PW. 2009. Divergência genética entre acessos de cenoura pertencentes a grupos varietais distintos utilizando caracteres morfológicos. Horticultura Brasileira 27: 473-477.

VIEIRA JV; SILVA GO; CHARCHAR JM; FONSECAMEN; SILVAJBC; NASCIMENTO WM; BOITEUX LS; PINHEIRO JB; REIS A; RESENDE FV; CARVALHO ADF. 2012. BRS Planalto: cultivar de cenoura de polinização aberta para cultivo de verão. Horticultura Brasileira 30: 359-363.

VILELA NJ; MORELLI JB; MAKISHIMA N. 1997. Impactos socioeconômicos da pesquisa de cenoura no Brasil: 1977-1996. Brasília: Embrapa Hortaliças, 20p. (Documentos, 11). 